\title{
UNCONFINED CREEP OF POLAR SNOW
}

\author{
By René O. Ramseier and Thomas L. Pavlak* \\ (U.S. Army Cold Regions Research and Engineering Laboratory, Hanover, New Hampshire, \\ U.S.A.)
}

\begin{abstract}
Snow samples from the Amundsen-Scott South Pole station and "Byrd" station, Antarctica, and "Camp Century", Greenland were tested for creep under low stresses for various periods of time up to two years. Creep was analyzed as a function of density. Comparisons of compressive viscosities plotted against densities for all three sites showed three distinct regions representing three different mechanisms of densification.

RÉsumé. Des échantillons de neige des Stations "Amundsen-Scott" (Pôle Sud) et "Byrd", Antarctique et "Camp Century" au Groenland ont été testés pour le fluage sous de faibles contraintes pour des périodes de temps différentes allant jusqu'à deux ans. Le fluage a été analysé en fonction de la densité. La comparaison des viscosités à la compression représentées en fonction de la densité montre pour chacune des trois stations trois régions distinctes représentant trois mécanismes différents de densification.

Zusammenfassung. Kriechversuche mit freier Seitenausdehnung wurden an Schneeproben von der Amundsen-Scott South Pole Station und der "Byrd Station" in der Antarktis sowie von "Camp Century" in Grönland durchgeführt. Die Druckspannungen waren klein; die Versuchszeiten variierten zwischen einigen Tagen und zwei Jahren. Die Kriechvorgänge wurden als Funktionen der Dichte analysiert. Der Vergleich von Diagrammen, in denen die Druckviskosität in Abhängigkeit von der Dichte für alle 3 Testorte dargestellt ist, ergibt drei klar erkennbare Bereiche mit unterschiedlichen Verdichtungsvorgängen.
\end{abstract}

\section{INTRODUCTION}

Creep is the time-dependent deformation of solids under stress, where deformation rates due to the stresses are small enough so that failure does not occur. There is a distinct similarity of creep features in many different materials which has not yet been explained. The essential features exhibited by creep curves are: an instantaneous strain, a transient creep of decreasing rate, and a steady-state creep, approximately linear with time. At the present time there is not enough information on isolated processes to compile a comprehensive theory of creep behavior of snow as an aggregate.

\section{Experimental Procedure}

Three locations were used in the creep study of snow under low stresses. Tests were run at "Camp Century", Greenland, for over two years, and tests were made over shorter periods at "Byrd" station and Amundsen-Scott South Pole station in the Antarctic. Undersnow rooms served as laboratories at all three locations. Temperature variations during the experimental period were $\pm 0.5^{\circ}$ C. for "Camp Century" and less at the Antarctic stations.

Two different experimental apparatuses were used for the present study. For the long-term tests, snow blocks and snow cylinders were loaded directly with dead weights, and the amount of deformation was measured by Starrett dial gauges, vertically mounted at $0^{\circ}, 90^{\circ}, 180^{\circ}$, and $270^{\circ}$, equidistant from the center of the sample. The four readings from each block were then averaged to determine total vertical deformation. Apparatus designed by Butkovich and Landauer (1960) was used for the short-term tests. Snow samples were cut to approximately $2 \times 2 \times 6 \mathrm{~cm}$. and then compressed uniaxially at the center of an aluminum beam pivoted at one end with weights attached to the free end. A steel ball at the center of the beam transmitted the force through an aluminum plate frozen to the snow sample, and a mechanical Starrett dial gauge was mounted at the free end of the beam where deflections could be read to an accuracy of $\pm 0.0002 \mathrm{~cm}$. The entire apparatus consisted of twelve such units mounted on aluminum plates in groups of four.

Table I indicates basic information for the samples tested. The values given express the limits of the ranges studied.

* Formerly U.S. Army Specialist; present address: $53^{14} 4$ S. Mayfield, Chicago 38, Ill., U.S.A. 
Table I. Summary of Conditions of Tests

Sample size, $\mathrm{cm}$.

Density, $\rho$ g. $\mathrm{cm}^{-3}$

Stress, $\sigma \dagger$ g. cm..$^{-2}$

Temperature, $T^{\circ} \mathrm{C}$.

\section{South Pole}

$2 \times 2 \times 6$ and*

7.5 dia. $\times 18$ height

$0.40-0.65$

$77-166$

$-48 \cdot 0$
"Byrd" station
$7 \cdot 5$ dia. $\times 18$ height
$0 \cdot 44^{-0} \cdot 54$
$214-464$
$-25 \cdot 0$

$$
\begin{gathered}
\text { "Camp Century" } \\
25 \times 25 \times 25 \\
0.38-0.60 \\
168-511 \\
-22.5
\end{gathered}
$$

* The $2 \times 2 \times 6 \mathrm{~cm}$. samples were tested during the austral summer of $196 \mathrm{r}-62$ (Ramseier, r 963 ) and were short-term tests. All other samples were long-term tests. The $7 \cdot 5 \mathrm{~cm}$. dia. $\times 18 \mathrm{~cm}$. height samples were tested during the austral summer of $1962-63$.

† One-half the sample weight is included in the load (Landauer, 1955).

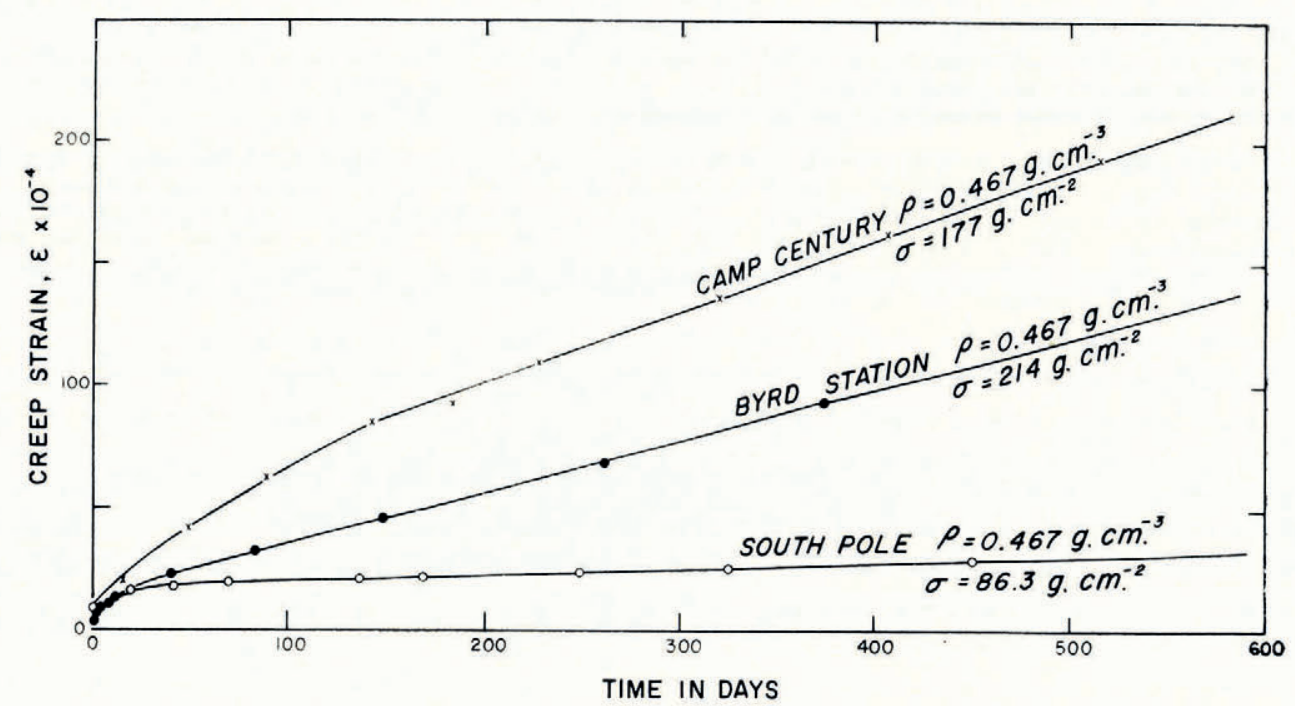

Fig. I. Creep strain versus time for all test sites

Because of the small strains, it was assumed that the constant load did not appreciably affect the cross-sections, and the problem could be treated as one of constant stress. All samples were taken directly from pits and walls at the experimental sites. Particular care was taken to select snow samples which were more or less "homogeneous", i.e. did not contain ice lenses or layers of depth-hoar crystals.

\section{Results}

Part A. Power function

Figures I and 2 show some typical strain versus time curves from "Camp Century", South Pole and "Byrd" station. The higher curve for "Camp Century" in Figure 2 represents the test for snow of very low density and the change in slope is attributed to an increase in density of the sample at a high strain-rate.

As can be seen from the figures, a power function

$$
\epsilon=\epsilon_{0}+b t^{n}
$$

can be applied. $\ddagger$ Here $\epsilon_{0}$ is an instantaneous extension, $b$ and $n$ are constants. Values for the constants $b$ and $n$ at each site are given in Table II.

‡ The power function was used to extrapolate data taken during the austral summer $196 \mathrm{I}-62$ at the South Pole as shown in Figure 2. 


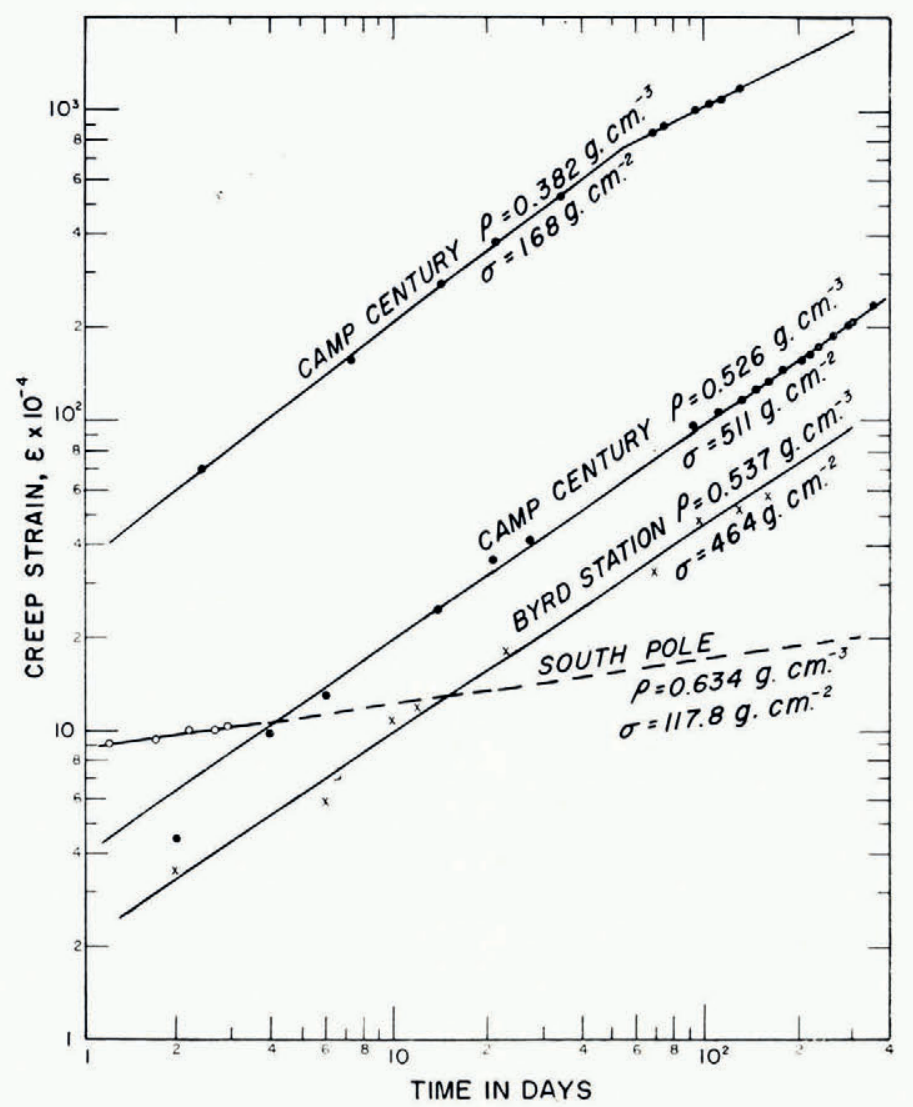

Fig. 2. Creep strain versus time for all test sites, logarithmic scales

Table II. Values of Constants in the Transient Creep Law

$\begin{array}{lccc} & \text { South Pole } & \text { "Byrd" station } & \text { "Camp Century" } \\ \rho \mathrm{g} . \mathrm{cm} .^{-3} & 0.63 & 0 \cdot 54 & 0.53 \\ \epsilon_{0} & 6 \cdot 04 \times 10^{-5} & 9 \cdot 28 \times \mathrm{IO}^{-3} & 9.63 \times \mathrm{IO}^{-3} \\ b & 8 \cdot 4 \mathrm{I} \times 1 \mathrm{O}^{-4} & 2 \cdot \mathrm{I} \mathrm{I} \times \mathrm{IO}^{-4} & 4.53 \times 1 \mathrm{O}^{-4} \\ n & 0 \cdot 145 & 0.64 \mathrm{O} & 0.690\end{array}$

Andrade's equation (1910, 1962) was also tried for some of the typical creep curves, this is of the form

$$
\epsilon=\epsilon_{0}+\beta t^{\frac{1}{3}}+k t
$$

where $\epsilon_{0}, \beta, k$ are constants. Exponents of $\frac{2}{3}$ and $\frac{1}{2}$ were also tried instead of $\frac{1}{3}$ in equation (2). Andrade and Jolliffe (196r) point out that at lower strains for lead the above mentioned laws were found to be valid. A comparison with present data showed that the ordinary power law equation (I) fitted the data better, i.e. the standard deviation was smaller.

Part B. Rheological model

Figure 3 shows a typical creep curve for tests conducted over a long period ( $\mathrm{I}$ to $2 \mathrm{yr}$.) at "Camp Century". Observations indicate an extended time period of from roo to $35^{\circ}$ days in the transient creep stage before constant viscous flow was attained. Later tests were conducted in the Antarctic during the summer of $1962-63$ and a transient creep period of 90 days was 


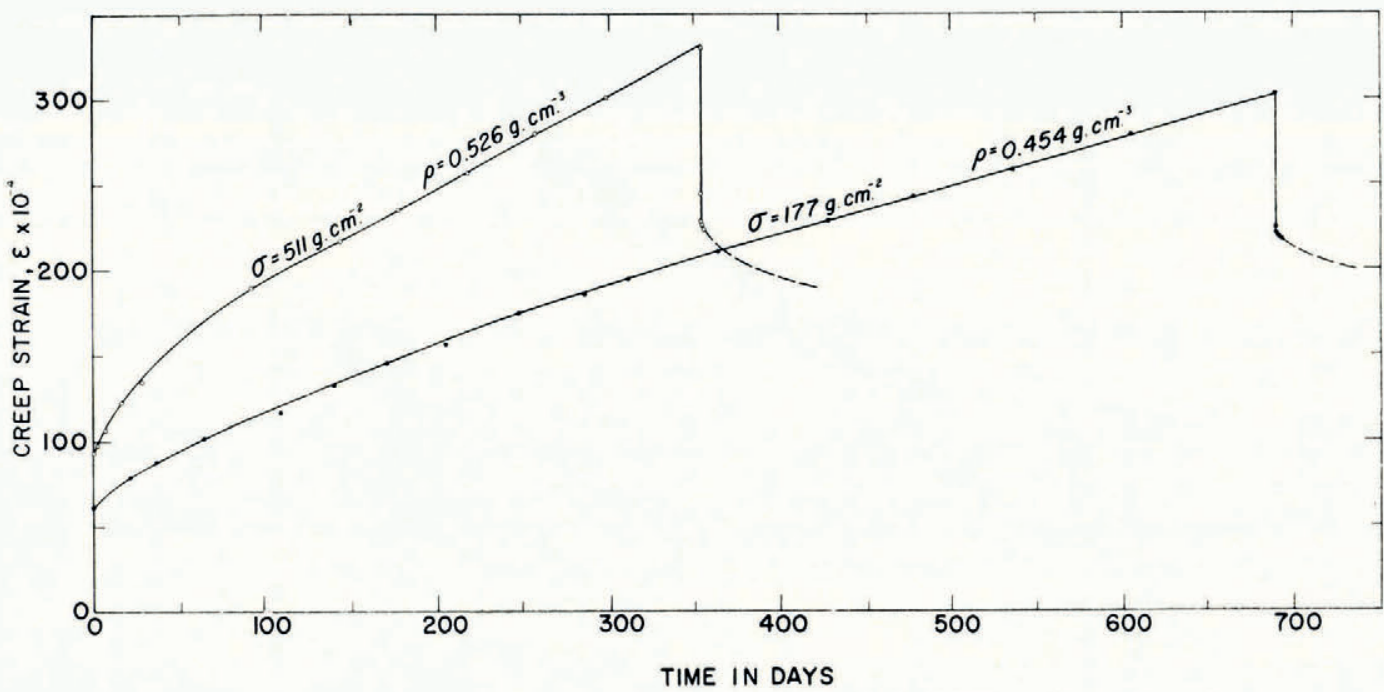

Fig. 3. Creep strain versus time, and relaxation after removal of load, for "Camp Century" samples

recorded under the South Pole test conditions outlined in Table I. Three variables (density, stress, and temperature) were observed to affect the length of time in transient creep. A low density snow would have more transient creep than a higher density snow, while a lower temperature or higher stress would reduce the transient creep. In metals they would increase the transient creep. Since the experiments run at the South Pole during the summer of I 96 I -62 were terminated after only ten days, it was necessary to extrapolate the data to a point of constant viscous flow in order to compare viscous strain-rate $\dot{\epsilon}$ and compressive viscosity $\eta_{\mathrm{c}}$. The results for the South Pole, as indicated in Figure 4, show a good correlation with the independent tests conducted by the authors over two years with different testing apparatus, as described previously in the text.

The data as shown in Figure 3 show a similarity to Yosida's results (1956). The rheological model used is composed of a Maxwell unit and Voigt unit connected in series. An expression for total strain as represented by this model is

$$
\epsilon=\frac{\sigma}{E_{\mathrm{I}}}+\frac{\sigma t}{\eta_{\mathrm{I}}}+\left[\frac{\sigma}{E_{2}}\left(\mathrm{I}-e^{-t / \tau}\right)\right] .
$$

The first term $\sigma / E_{\mathrm{I}}$ in the equation represents instantaneous elastic strain where $\sigma$ is applied stress and $E_{\mathrm{I}}$ is the elastic modulus. Constant strain-rate corresponding to viscous flow is indicated in the second term $\sigma t / \eta_{\mathrm{I}}$ where $t$ is time and $\eta_{\mathrm{I}}$ is compressive viscosity. This second term could also be defined as steady-state creep. The final part of the expression is the transient creep or decreasing strain-rate where $E_{2}$ is an elastic constant of the Voigt unit, and $\tau$ is the retardation time. It was assumed that in our test the strain rate is proportional to stress (Landauer, I955; Yosida and others, 1956).

Table III gives values for tests conducted at "Camp Century", Greenland at a temperature of $-22 \cdot 5^{\circ} \mathrm{C}$.

Table III. Rheological. Parameters Deduced from the Tests at “Camp Century”, Greenland

\begin{tabular}{|c|c|c|}
\hline & Series I & Series 2 \\
\hline $\begin{array}{l}\rho \mathrm{g} \cdot \mathrm{cm} \cdot \cdot^{-3} \\
E_{\mathrm{I}} \mathrm{g} \cdot \mathrm{cm} \cdot{ }^{-2}\end{array}$ & $\begin{array}{l}0.53 \\
4.135 \times 10^{4}\end{array}$ & $\begin{array}{l}0.4^{6} \\
2 \cdot 7^{8} 7 \times 10^{4}\end{array}$ \\
\hline$\eta_{1}$ g. sec. $\mathrm{cm}^{-2}$ & $85 \cdot 75 \times 10^{10}$ & $4 \mathrm{I} \cdot 14 \times 10^{10}$ \\
\hline$E_{2} \mathrm{~g} . \mathrm{cm}^{-2}$ & $14.17 \times 10^{4}$ & $3.00 \times 10^{4}$ \\
\hline$\tau$ sec. & $2.575 \times 10^{6}$ & $7.753 \times 10^{6}$ \\
\hline
\end{tabular}


Figure 4 represents a composite plot of compressive viscosity versus density for the three locations. Values for the compressive viscosity were found by using the steady-state creep region where the strain-rate is constant. Bader (1963) gives an expression for the "densification viscosity factor" $\eta_{\mathrm{c}}$ which the authors call "compressive viscosity" for the case of unconfined compression.*

$$
\eta_{\mathrm{c}}=\frac{a \rho}{\rho_{\mathrm{i}}-\rho} e^{b \rho}
$$

where $a$ and $b$ are constants dependent upon site conditions and $\rho_{i}$ is the density of ice. Applying Bader's expression and constants for both South Pole and "Byrd" station (Table IV), two straight lines are obtained as shown in Figure 4.

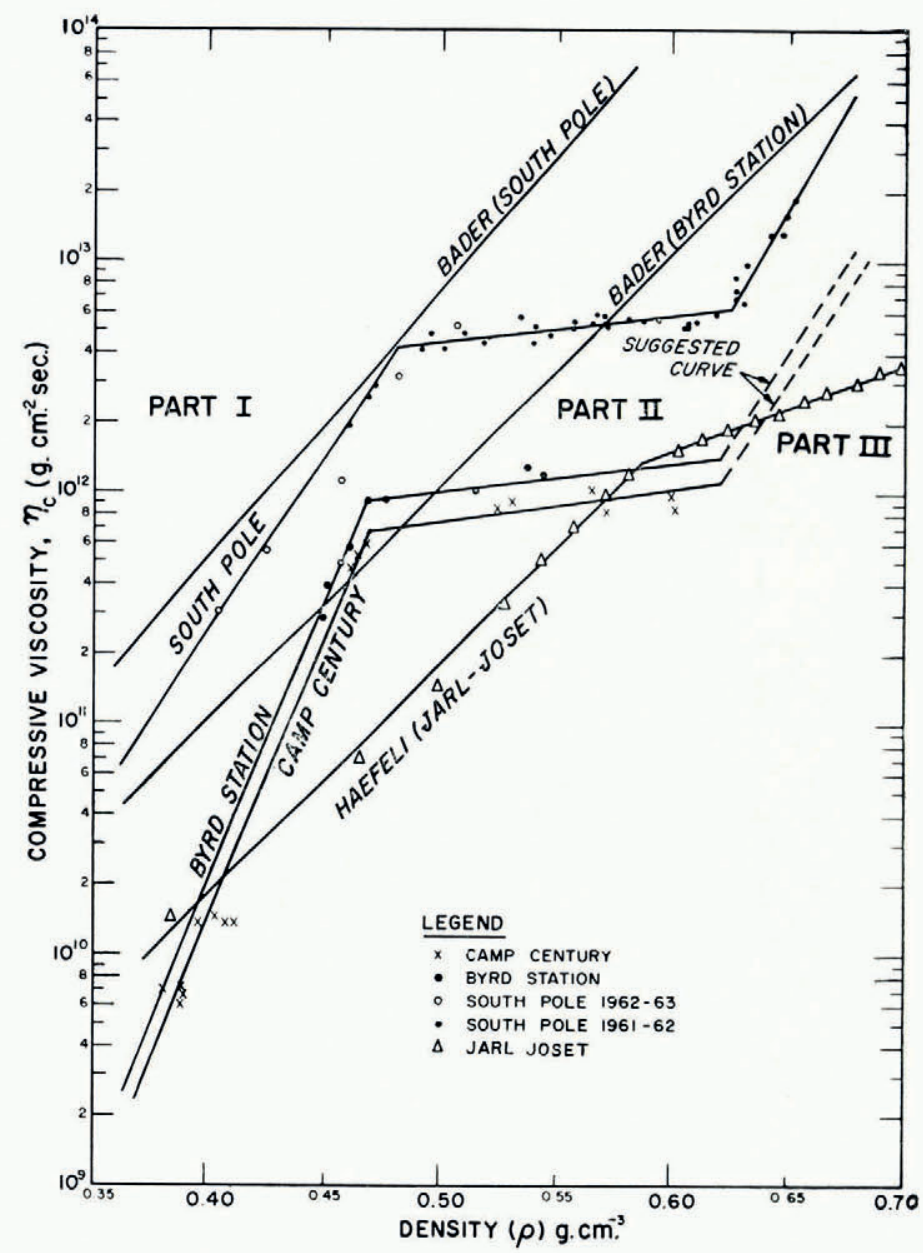

Fig. 4. Compressive viscosity versus density for all test sites, logarithmic scale for viscosity. Results of confined compressive tests by Bader and Haefeli are added for comparison

* Bader's units for $\eta_{\mathrm{c}}$ are in $\mathrm{g} . \mathrm{yr}, \mathrm{cm} .^{-2}$ and a conversion from years to seconds is necessary for corresponding values in Figure 4 . 
Table IV. Constants in Bader's Expression for Densification Viscosity Factor

\begin{tabular}{|c|c|c|}
\hline & South Pole & "Byrd" station \\
\hline $\begin{array}{l}a \text { g.sec.cm. } .^{-2} \\
b \text { cm } .^{3 \mathrm{~g},-1}\end{array}$ & $\begin{array}{r}3 \cdot 617 \\
21 \cdot 68\end{array}$ & $\begin{array}{l}3 \cdot 140 \\
18 \cdot 10\end{array}$ \\
\hline$\rho_{\text {i }}$ g.cm. ${ }^{-3}$ & 0.917 & $0 \cdot 917$ \\
\hline
\end{tabular}

\section{Discussion}

Yosida (1956) applied classical rheology to his unconfined creep studies of snow. Our data, when treated in a similar manner, yielded good results. The composite graph of the compressive viscosity $\eta_{\mathrm{o}}$ versus density $\rho$ is shown in Figure 4 . There is a rapid change in slope at the density $0.47 \mathrm{~g} . \mathrm{cm}^{-3}$ and again at $0.625 \mathrm{~g} . \mathrm{cm} .^{-3}$. Yosida's (Yosida and others, I956, p. I-I 4 ) data correspond to the general trend of the Figure 4 curves in the low density region $(\rho<0.47)$. For the density range $0.47<\rho<0.625$, it was found that the compressive viscosity is nearly constant. This region will be referred to as the "plateau" region. Data from the South Pole indicate that when the density is greater than $0.625 \mathrm{~g} . \mathrm{cm} .{ }^{-3}$ the slope steepens to a higher value. The data from "Byrd" station and "Camp Century" do not include the high density range $(\rho>0.625)$, but it is believed that the trend will be similar to the South Pole curve. This is shown by the suggested curve.

In the "plateau" region there seems to be a rearrangement of snow grains without an appreciable change in viscosity. The activation energy for creep was calculated by applying the expression;

$$
\eta_{\mathrm{c}}=\eta_{\mathrm{o}} e^{Q / R T}
$$

where $\eta_{0}$ and $Q$ are constants characteristic of the material tested, $R$ is the universal gas constant and $T$ the absolute temperature for the snow at all three stations.

If the activation energy for the "plateau" region is calculated and the operation is extended through the density range $0 \cdot 47<\rho<0 \cdot 625$, the activation energy $Q$ is $7 \cdot 2 \mathrm{kcal}$. mole ${ }^{-1}$. This value is very low, only slightly higher than the energy needed to break one hydrogen bond. The indication here is that a single process dominates this "plateau" region.

Yosida reported activation energies for low-density snow $\left(0 \cdot 17\right.$ to $\left.0.25 \mathrm{~g} . \mathrm{cm} .{ }^{-3}\right)$, varying from $20 \cdot 8$ to $23 \cdot 8 \mathrm{kcal}$. mole ${ }^{-1}$ respectively. By extrapolating the viscosity curve to the low densities and calculating activation energies, partial agreement with Yosida's values is found. There is actually a "varying" activation energy for the low densities (less than $0.45 \mathrm{~g} . \mathrm{cm}^{-3}$ ) and then again for densities greater than $0.66 \mathrm{~g} . \mathrm{cm} .^{-3}$ up to ice. Landauer (1955, I957) obtained values of $\mathrm{I} 3.4$ and $\mathrm{I} 4 \cdot \mathrm{o}$ kcal. mole ${ }^{-1}$ for densities between $0 \cdot 38$ and $0 \cdot 4^{2} \mathrm{~g} . \mathrm{cm}^{-3}$. According to our results, a large change in activation energy occurs with a small change in density in the above density range. Butkovich and Landauer (1960) point out that the activation energy for ice $\left(14 \cdot 3 \mathrm{kcal}\right.$. mole $\left.{ }^{-1}\right)$ agrees with the previously calculated values for snow. It would appear that coincidentally Landauer obtained these results for snow by working within the only density range in which there is an agreement in activation energy between snow and ice. Table $\mathrm{V}$ summarizes the values for activation energies found by the various investigators in different density ranges.

Table V. Values for the Activation Energy for Steady-State Creep of Ice found by Various INVESTIGATORS

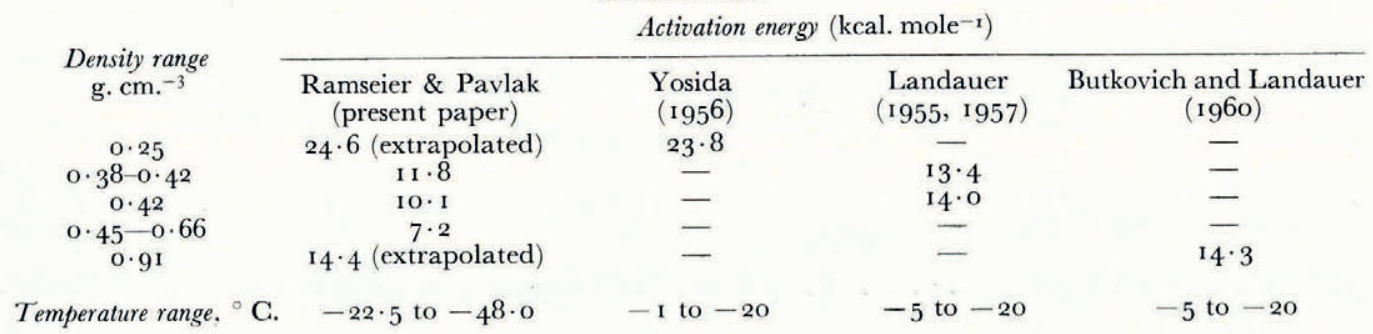


A possible explanation of the rapid change is that the activation energies in the high and low-density regions are the mean values for more than one process. However, this reasoning is questionable.

As has already been pointed out by Ramseier ( 1963 ), and substantiated by these data, there is more than one mechanism of densification operating over the whole density range. The entire process is a rather complicated one even if it is separated into three distinct regions.

It is interesting to note that the air permeability curve (Ramseier, r963, fig. 3) shows a change in slope at the same density $\left(0.625 \mathrm{~g} . \mathrm{cm}^{-3}\right)$ as the viscosity curve. At $\rho>0.625$ grains are deformed so that closure of air passages is effected to the extent that air can no longer pass freely around each grain. Air is trapped by the deforming grains to form air pockets, which in this stage of ice are evidenced by bubbles. This mechanism, deformation rather than packing and rearranging of grains, affects the creep as can be seen by the dramatic change in slope at density 0.625 g. cm. ${ }^{-3}$ (Fig. 4). The major mechanism governing the low-density region (Part I) is one of breaking bonds and "large" displacement in the structure.

The "plateau" region is of considerable interest in engineering problems where low stresses are applied. The desirability of having an almost constant strain-rate for a rather large part of the density profile would be evident in design to allow for settlement. Of course there is the question of how unconfined creep compares with creep of a block of snow in situ. The best viscosity values now available for natural conditions are obtained using Bader's constants (Table IV). These values were plotted in Figure 4. It can be seen that the curves have approximately the same trend as the presently reported values up to the point where the "plateau" region appears and then again in the higher density range. This change of slope can be attributed to the fact that Bader's analysis represented a smooth curve over the whole density range, while a more specific range of densities was used in this report.

Haefeli's values (personal communication) for unconfined creep from the "Jarl-Joset" station (mean annual temperature $-27 \cdot 8^{\circ} \mathrm{C}$.) are also shown in Figure 4 . Part I of his curve is in good agreement with Bader's. The change in slope occurs at a density of $0.5^{8} \mathrm{~g} . \mathrm{cm} .^{-3}$, which is much higher than the ones for the other stations. This may be due to the fact that Haefeli's were confined creep tests. Mellor and Hendrickson (in press) also conducted confined creep tests at "Byrd" and South Pole stations. The general trend of their data agrees with the authors' but the scatter is large and the data are inconclusive for determination of the plateau region. Further confined creep tests of this type are needed.

\section{ACKNOWLEDGEMENTS}

This project was supported in part by the National Science Foundation, Office of Antarctic Programs. The authors would like to express their indebtedness to this group and also to Edward Oliver for his valuable assistance in the field work at the South Pole. Due to the length of experimental run at "Camp Century", Greenland, it would be difficult to mention all the persons who provided assistance to the program, but special gratitude is given to Ernest Holt and Tom Long for their extra effort. Further appreciation is extended to Johannes Weertman for his critical review of the manuscript.

MS. received 17 March 1964

\section{REFERENCES}

Andrade, E. N. da C. r9 го. On the viscous flow in metals, and allied phenomena. Proceedings of the Royal Society, Ser. A, Vol. 84 , No. 567 , p. I-I 2 .

Andrade, E. N. da C. 1962 . The validity of the $t^{\frac{1}{3}}$ law of flow of metals. Philossphical Magazine, Eighth Ser., Vol. 7, No. 84 , p. $2003-14$.

Andrade, E. N. da C., and Jolliffe, K. H. 1961. Creep of metals under simple shear. Nature, Vol. 190, No. 4774, p. $431-32$. 
Bader, H. 1963. Theory of densification of dry snow on high polar glaciers. II. (In Kingery, W. D., ed. Ice and snow; properties, processes, and applications: proceedings of a conference held at the Massachusetts Institute of Technology, February $12-16,1962$. Cambridge, Mass., The M.I.T. Press, p. $35^{1-76 .)}$

Butkovich, T. R., and Landauer, J. K. 1960. Creep of ice at low stresses. U.S. Snow, Ice and Permafrost Research Establishment. Research Report 72.

Landauer, J. K. I955. Stress-strain relations in snow under uniaxial compression. U.S. Snow, Ice and Permafrost Research Establishment. Research Paper 12.

Landauer, J. K. 1957. Creep of snow under combined stress. U.S. Snow, Ice and Permafrost Research Establishment. Research Report 41.

Mellor, M., and Hendrickson, G. In press. Creep tests in polar snow. U.S. Cold Regions Research and Engineering Laboratory. Research Report ${ }_{1} 38$.

Ramseier, R. O. ${ }_{1963}$. Some physical and mechanical properties of polar snow. Journal of Glaciology, Vol. 4, No. 36, p. $753-69$.

Yosida, Z., and others. 1956. Physical studies on deposited snow. II. Mechanical properties ( I), by Z. Yosida, H. Oura, D. Kuroiwa, T. Huzioka, K. Kojima, S. Aoki and S. Kinosita. Contributions from the Institute of Low Temperature Science, No. 9, p. I-81. 